\title{
O uso de tecnologias por famílias de agricultores: uma reflexão metodológica
}

\section{The use of technology by farm families: a methodological reflection}

Ana Carolina Damboriarena Escosteguy ${ }^{1}$

Lirian Sifuentes ${ }^{2}$

Aline Bianchini ${ }^{3}$

Resumo Este trabalho tem por objetivo realizar uma discussão metodológica sobre uma pesquisa acerca das experiências de apropriação de tecnologias de comunicação por famílias de agricultores integradas à cadeia agroindustrial do tabaco. A incursão a campo em que se baseia o relato foi realizada junto a duas famílias moradoras da região de Santa Cruz do Sul - RS. Tendo em vista a importância da metodologia para a pesquisa empírica, a reflexão proposta mostra-se produtiva para analisar o trajeto já percorrido e para projetar os próximos passos do trabalho.

Palavras-chave: Metodologia; tecnologias de comunicação; usos da mídia; famílias agricultoras

Abstract This paper aims to present a methodological discussion of an investigation about communication technologies uses experience by farm families integrated into the tobacco agro-industrial chain. The field work

\footnotetext{
${ }^{1}$ Pontifícia Universidade Católica do Rio Grande do Sul - PUC/RS. Porto Alegre, Rio Grande do Sul, Brasil.

E-mail: carolad@pucrs.br

${ }^{2}$ Pontifícia Universidade Católica do Rio Grande do Sul - PUC/RS. Porto Alegre, Rio Grande do Sul, Brasil.

E-mail: lisifuentes@yahoo.com.br

${ }_{3}$ Pontifícia Universidade Católica do Rio Grande do Sul - PUC/RS. Porto Alegre, Rio Grande do Sul, Brasil.

E-mail: li.bianchini@gmail.com
} 
98 O USO DE TECNOLOGIAS POR FAMÍLIAS DE AGRICULTORES

that underlies this paper was carried out with two families of farmers, residents of Santa Cruz do Sul region (RS). We believe that, given the importance of methodology for empirical research, our reflection shows up productive by analyzing the choices and decisions, and to design the next steps of the research.

Keywords: Methodology; communication technologies; media uses; farm families 


\section{Introdução}

Este trabalho tem por objetivo realizar uma discussão fundamentalmente metodológica sobre a pesquisa "Tecnologias de comunicação nas práticas cotidianas: o caso de famílias relacionadas à cadeia agroindustrial do tabaco" (CNPq, 2014-2016) de modo a servir para a continuidade da investigação empírica que estamos realizando, bem como para o aproveitamento por outras pesquisas com objetivos semelhantes. O desafio é adotar, ainda que de modo parcial, a reflexividade (NEVES e NOGUEIRA, 2005) no processo da pesquisa, examinando e questionando as práticas e procedimentos adotados até o momento.

A investigação foca na reconstituição de práticas cotidianas e nas experiências de apropriação de um determinado grupo social: famílias de agricultores integradas à cadeia agroindustrial do tabaco em sua relação com tecnologias de comunicação, compreendendo tanto a mídia tradicional (rádio, televisão, jornal e revista) quanto a nova mídia (telefone celular, computador e internet) nas suas inter-relações. É de fundamental importância manter sob escrutínio a relação que se estabelece entre meios novos e antigos, pois tal enfoque colabora para manter em tensão as mudanças e inovações técnicas e as formas sociais e dinâmicas culturais constituídas no cotidiano (MORLEY, 2008; VARELA, 2010).

Junto com Martín-Barbero (2009, p. 148), compreendemos que a tecnologia não é apenas uma coisa, mas um “âmbito’ extremamente potente, tanto de linguagens como de ações, tanto de dinâmicas sociais, políticas e culturais, quanto de interrogações sobre o que significa o social hoje”. Assim, ela extravasa seu próprio espaço e caráter meramente instrumental, constituindo novas formas de sociabilidade e funções rituais.

Entendidas tanto como artefatos/objetos quanto como meios, as TICs são adquiridas seja por motivos funcionais seja por opção estética e/ou de status. Como meios, proporcionam laços - entre famílias, membros individuais das mesmas e o mundo que está fora da moldura do lar; por isso, Silverstone, Hirsch e Morley (1996, p. 40) avaliam que elas estão "duplamente articuladas em culturas privadas e culturas públicas". 
Embora o foco não seja a discussão do referencial teórico adotado na presente pesquisa, salientamos que está situada no âmbito dos estudos de consumo e de usos de TICs no contexto doméstico, em especial aquelas orientadas pelas formulações de Silverstone, Hirsch e Morley (1996). Além desse marco teórico, seguimos as contribuições de Couldry (2009, 2010, 2013), Morley (2008) e Silverstone (2005). Todos eles, de alguma forma, entendem que o desafio tecnológico não tem origem na tecnologia em si mesma, mas, principalmente, no papel que os meios exercem na vida cotidiana, enfim, nos seus usos e rituais.

Faz-se necessário, então, compreender o processo de domesticação pelo qual as distintas tecnologias de informação e comunicação têm passado - sendo incorporadas ao lar, adquirindo significado na vida cotidiana e fazendo sentido nos marcos culturais, cognitivos e afetivos dos mais distintos sujeitos. E também incluir a descrição de um processo mais recente que se encaminha na direção contrária, como salienta Morley (2008, p. 145), de "desdomesticação" dos meios e de deslocamento radical da domesticidade.

No que diz respeito às famílias pesquisadas, envolvidas na produção agrícola de tabaco, os espaços de trabalho e de vida familiar se confundem, uma vez que é no ambiente doméstico que se realiza boa parte da atividade produtiva e com a mão de obra de toda a família. O contexto da agricultura familiar revela, então, a fusão das relações entre o mundo do trabalho e o espaço doméstico, sendo também o ambiente de consumo das TICs. Tendo em vista que o contexto exerce importante influência sobre como as tecnologias são percebidas, adotadas e utilizadas pelos indivíduos (MORLEY, 2008), entendemos a importância da compreensão do contexto rural, da agricultura familiar e da região para esta pesquisa, levando em consideração suas características históricas, econômicas e socioculturais.

As incursões a campo que deram origem a este artigo foram realizadas no município de Vale do Sol, microrregião de Santa Cruz do Sul - RS, junto a duas famílias agricultoras. Cada família foi visitada duas vezes em julho e em outubro de 2014. Nesses encontros, foram empregadas 
como técnicas de investigação: ${ }^{4}$ formulários; entrevista aberta coletiva; entrevista semiestruturada individual; observação e registro fotográfico. A pesquisa empírica foi desenvolvida em duas etapas, que correspondem à primeira e à segunda visitas: a) levantamento de dados objetivos, como uma primeira sondagem, mediante o uso de um formulário sociocultural que aborda informações gerais da família e da propriedade, indaga sobre quais tecnologias de comunicação estão presentes nos lares e como os membros das famílias as utilizam, bem como quais são as outras tecnologias domésticas existentes na casa; b) implementação de uma entrevista junto aos membros das famílias selecionadas com o objetivo de reconstituir suas práticas em relação às tecnologias da comunicação.

Na sequência deste artigo, apresentamos o desenho metodológico da investigação, especialmente no que se refere aos procedimentos de coleta de dados que estão sendo empregados; uma reflexão sobre cada um dos instrumentos de coleta e, em casos específicos, o manuseio inicial dos dados coletados; e, por fim, apontamentos acerca da continuidade da pesquisa. Julgamos que, tendo a metodologia um papel tão basilar em qualquer estudo empírico, o exercício de reflexão proposto mostra-se produtivo para analisar o trajeto percorrido, as escolhas e decisões, e para projetar os próximos passos do trabalho. Assumimos, dessa forma, que um dos valores da reflexividade reside na adoção de designs flexíveis de investigação, o que propicia espaço de aprendizagem tanto para aqueles diretamente envolvidos na investigação quanto para a comunidade acadêmica em geral. Ao optar por essa direção, este relato não pretende adiantar resultados nem conclusões a respeito da pesquisa empírica em andamento.

Vale ressaltar que, no caso específico desta pesquisa, o universo rural investigado é relativamente desconhecido das pesquisadoras, já que toda nossa vida social se constituiu no ambiente urbano. Essa condição torna "mais fácil pesquisar sobre universos desconhecidos, porque sua estranheza cria distância e obriga a ver com olhos novos fenômenos que

${ }^{4}$ Adiante detalharemos as respectivas técnicas implementadas. 
seriam esquecidos se tais meios fossem familiares" (BEAUD e WEBER, 2007, p. 37).

\section{Incursões a campo: pesquisados e instrumentos de pesquisa}

Para esta reflexão metodológica, tomamos como base as experiências empíricas realizadas em 2014 para a referida pesquisa. Elas se traduzem em duas incursões a campo: a primeira realizada em 17 de julho e a segunda, em 6 de outubro. Ambas basearam-se em visitas a duas famílias de agricultores, as famílias V. e K., ${ }^{5}$ moradoras de Vale do Sol.

A família V. é composta por três membros: pai (30 anos), mãe (30 anos) e filho (oito anos). A propriedade da família conta com 11 hectares, nos quais se cultivam tabaco (cerca de 90 mil pés por ano), milho, feijão, batata, batata-doce, aipim, abóbora e verduras em geral, além de serem criados porcos e galinhas. Já a família K. é composta por quatro membros: pai (39 anos), mãe (37 anos), filho (20 anos) e filha (11 anos). $\mathrm{Na}$ propriedade de 22 hectares são produzidos tabaco, leite, frutas, mel, feijão, batata, batata-doce, mandioca, verduras, além de uma pequena criação de gado, porcos e galinhas.

Os procedimentos com as duas famílias foram os mesmos. ${ }^{6} \mathrm{Na}$ primeira visita, fizemos uma introdução a que chamamos simplesmente de apresentação: uma conversa inicial esclarecendo sobre a pesquisa e apresentando os pesquisadores; em seguida, aplicação de um formulário individual incluindo questões relativas à família, à educação e ao consumo de mídia; por fim, um formulário de família, enfocando aspectos da casa e da propriedade. Na segunda ida a campo, retornamos às casas das famílias V. e K. e realizamos entrevistas individuais. Enquanto na primeira visita todos os pesquisadores (seis) estiveram juntos em cada

\footnotetext{
${ }^{5}$ No relato, os nomes das famílias foram ocultados, utilizando-se apenas sua primeira letra. Tendo em vista o amplo acesso a textos científicos na internet, buscamos evitar o reconhecimento das famílias - que mantêm certa proximidade e vínculo social.

${ }^{6}$ A apresentação dos instrumentos será aprofundada na sequência deste artigo.
} 
uma das casas, na segunda dividimo-nos em grupos de dois e quatro, de acordo com o número de membros de cada família. ${ }^{7}$

O contato com as famílias foi intermediado por um engenheiro agrônomo de uma organização não governamental que atua na microrregião de Santa Cruz do Sul. ${ }^{8}$ A ONG presta serviços às famílias das comunidades onde vivem nossos pesquisados há muitos anos e o agrônomo conhece alguns informantes desde a infância. Foi dele a escolha das duas famílias - num encontro prévio à ida ao Vale do Sol, explanamos os propósitos gerais da pesquisa, assim como ele nos relatou a realidade da localidade -, ambas notáveis usuárias das novas tecnologias de comunicação. ${ }^{9}$

A seguir, detemo-nos em apresentar e refletir sobre a experiência de campo e cada um dos instrumentos de coleta de dados utilizado, bem como sobre a primeira organização mais compreensiva de alguns dados obtidos a partir dessas experiências empíricas, que resultaram no que denominamos relato de campo ${ }^{10}$ e perfil individual e familiar.

\subsection{Chegar no campo}

Geralmente, não vemos relatos desse primeiro contato dos pesquisadores com seus pesquisados. Embora seja um aspecto básico em pesquisas empíricas, parece que se entende que sua característica "elementar" dispensa uma maior reflexão sobre sua realização. Sabemos, no entanto, que essa primeira aproximação é fundamental e sua preparação e execução não são tão simples na prática como parecem à primeira vista.

Primeiramente, vale comentar a respeito do papel do mediador. Sua atuação inicia na escolha das famílias a serem indicadas para participar da pesquisa. Ele realiza um filtro em relação ao tipo de informantes com quem haverá contato. Não foi solicitado a ele que as famílias possuíssem

\footnotetext{
7 A família V. é composta por dois adultos e uma criança e a família K., por três adultos e uma pré-adolescente.

8 A ONG chama-se Centro de Apoio ao Pequeno Agricultor (Capa).

9 Faz-se uma breve reflexão sobre essa mediação no item 2.1.

${ }^{10}$ A partir do que cada investigador viu e vivenciou no campo, é elaborada uma narrativa que passa a ser compartilhada entre todos os membros da equipe.
} 
acesso à internet em casa, por exemplo. No entanto, sabendo do que se tratava nosso estudo, achou importante usar isso como critério. $\mathrm{Na}$ sequência da pesquisa, em etapa que não está incluída neste artigo, essa atuação do mediador não foi mais necessária. A partir das famílias V. e K., foi possível acessar outras famílias e escolher perfis mais variados.

Outro aspecto relevante foi o fato dele nos acompanhar na primeira visita, apresentando-nos aos agricultores. Se, por um lado, entendemos que essa mediação facilitou nossa acolhida por parte das famílias, por outro, suas intervenções eram mais diretas do que gostaríamos, adiantando alguns questionamentos que não pretendíamos explicitar numa primeira sondagem - como nosso interesse central nas tecnologias de comunicação.

Como preparação para essa etapa, elaboramos perguntas abrangentes para guiar nossa conversa - e é dessa forma que a entendemos, como um guia, não como um roteiro. Foram três perguntas amplas: como é viver aqui? Como é a rotina da família? Como é o uso dos meios de comunicação pela família? Antes que essas perguntas fossem feitas, foi realizada a apresentação da pesquisa - a cargo do mediador (o engenheiro agrônomo) - e dos pesquisadores - cada membro do grupo se apresentou, dizendo seu nome e sua ocupação profissional.

A maior parte da equipe participou dessa primeira incursão: seis pesquisadores. $\mathrm{O}$ que poderia ser extremamente invasivo, visto o elevado número de pessoas, pôde, na prática, ser interpretado como uma "grande visita”, visto a boa receptividade por parte das famílias. Para que o número de "entrevistadores" não prejudicasse a organização da conversa, previamente elegeu-se uma "entrevistadora principal", aquela que seria a responsável por direcionar a conversa, na medida do possível e necessário, para que fossem respondidas as questões levadas a campo. A "apresentação" durou cerca de uma hora em cada família.

\subsection{Formulários individual e de família}

Com o objetivo de delinear os perfis de cada família e de seus membros, dois tipos de formulários foram aplicados na primeira visita ao 
Vale do Sol: um referente a informações individuais (de cada membro da família) e outro referente à família, ambos com questões objetivas. O primeiro foi aplicado a cada um dos membros da família, inclusive crianças, a fim de conhecer melhor os indivíduos que compõem o núcleo familiar, bem como para se ter uma ideia inicial acerca de seus gostos, hábitos e usos das TICs. O formulário é composto por dois grandes blocos: "Dados pessoais" e "Mídia". Entre os dados pessoais, os entrevistados foram questionados acerca de sua residência na infância (campo ou cidade), atividade profissional dos pais (antiga e atual) e irmãos, cursos realizados, escolaridade do entrevistado e de familiares e atividades principais de lazer. Já o segundo bloco traz perguntas acerca dos meios de comunicação utilizados - TV, rádio, jornal, revista, internet, livros - e as respectivas emissoras assistidas/ouvidas, os programas preferidos, os locais, horários e frequência de consumo dessas mídias, além da questão “Qual o seu meio de comunicação favorito?", que finaliza o guia de perguntas.

O segundo formulário, por sua vez, diz respeito a informações referentes ao núcleo familiar. Respondido por um membro escolhido pela própria família, o formulário também traz questões objetivas em dois grandes blocos: "Propriedade" e "Tecnologias Domésticas". O objetivo no primeiro grupo de questões é saber se a propriedade é própria - e, em caso positivo, desde quando -, o que a família produz, qual o tamanho da propriedade e quem trabalha nela, qual o rendimento familiar, quem mora na casa e quantos dormitórios e banheiros ela tem. No segundo, referente às tecnologias domésticas, o representante da família informa aos pesquisadores a respeito da posse (e quantidade) de alguns artefatos, como carro e moto (modelo e ano); eletrodomésticos - geladeira, freezer, fogão a gás, fogão a lenha, forno micro-ondas, forno elétrico, lava-roupas, tanquinho, lava-louça, aspirador de pó e ar-condicionado; aparelhos de mídia - TV, rádio, DVD, videocassete, home theater, videogame, telefone fixo, celular, celular com internet, computador, notebook e tablet; acesso à internet - por meio de que tipo de serviço e com que 
qualidade do sinal; posse de antena parabólica, de TV por assinatura e de assinatura de jornais e revistas.

Os instrumentos foram aplicados pelo entrevistador, que colocou seu nome no topo da página - tendo em vista que a equipe conta com um grande número de pesquisadores, é importante que cada formulário seja identificado para que eventuais dúvidas possam ser sanadas. Vale ressaltar que houve discrepâncias na forma de preenchimento dos formulários por parte dos pesquisadores, o que revelou a importância de mais reuniões para esclarecimento dos instrumentos de pesquisa e seus respectivos propósitos. Apesar do esforço da equipe em desenvolver os instrumentos em conjunto, a ida a campo revelou ter havido uma compreensão diversa dos instrumentos, motivada pelo fato de os investigadores serem provenientes de universidades distintas e de cidades diferentes.

Durante a aplicação dos formulários, também vimos a necessidade de cada membro da família ser inquirido separadamente em um cômodo da casa (ou fora dela) para que a entrevista de um não interferisse na do outro, seja pela influência de respostas (observada em uma família na qual uma jovem foi entrevistada), seja pelos ruídos que atrapalham a comunicação entrevistador-entrevistado.

\subsection{Entrevistas individuais}

Para Morley (1996, p. 261), a entrevista, além de permitir "que o investigador tenha acesso às opiniões e declarações conscientes das pessoas entrevistadas", também propicia o "acesso a termos e a categorias linguísticas $[. .$.$] em virtude dos quais as pessoas entrevistadas constroem$ seus mundos e a própria compreensão de suas atividades". Assim, a realização de entrevista individual foi considerada um passo natural para aprofundamento dos conhecimentos acerca dos indivíduos pesquisados.

De modo geral, a entrevista buscou contemplar a chegada e introdução das TICs nos respectivos ambientes/lugares de vivência, as representações e os imaginários em operação no que diz respeito às TICs, bem como as alterações e continuidades produzidas no entorno 
da vida prática. Para isso, o instrumento foi organizado em quatro eixos, criados após reuniões realizadas com o objetivo de refletir sobre os dados que já tínhamos e sobre os que queríamos obter: "experiência de incorporação das TICs” - explorando um viés histórico da chegada e dos usos dos meios; "experiência de usos das TICs" - enfocando os usos dados aos artefatos tecnológicos hoje; "experiência do uso do meio favorito" - permitindo um conhecimento mais aprofundado do uso de um meio específico, o preferido; e "trabalho" - buscando relacionar o uso dos meios de comunicação ao trabalho agrícola realizado.

Paralelamente ao roteiro de perguntas, produziu-se um documento para esclarecimento sobre os objetivos dos eixos e sobre a melhor forma de aplicar a entrevista. Esse é um tipo de recurso valioso quando se realiza uma pesquisa coletiva, interdisciplinar e interinstitucional, sobretudo considerando as formações diversas dos pesquisadores. O documento iniciava pontuando os seguintes aspectos:

\section{Observações:}

1) É importante que todos os pesquisadores tenham clareza do que se pretende em cada tópico, na medida em que serão entrevistas realizadas individualmente por um entrevistador, mas o resultado comporá um conjunto integrado de dados. Ou seja, temos que garantir que as questões sejam feitas e direcionadas de modo semelhante.

2) Para isso foi produzido um roteiro de questões que será aplicado com cada membro da família por entrevistador diferente. Este documento que aqui está sendo apresentado serve para esclarecer sobre o roteiro produzido. O roteiro possui perguntas "semidiretivas", que servem para que, ao fim da entrevista, tenhamos as mesmas informações fundamentais de cada entrevistado e, ao mesmo tempo, permita uma adaptação do andamento da entrevista de acordo com cada caso.

Mesmo com esse recurso, somado a um briefing antes da incursão a campo, percebeu-se um nível de apropriação do instrumento bastante diverso. Comparando a aplicação das entrevistas através das gravações, percebeu-se que nem todos os entrevistadores conheciam profundamente o roteiro, não estando aptos a desenvolver a entrevista de uma forma 
mais natural. Por isso, foi planejado um workshop para desenvolvimento da técnica de entrevista e para uma maior apropriação com o instrumento produzido, com o objetivo de uniformizar os procedimentos.

Por último, acerca das entrevistas individuais, destacamos que o grupo de pesquisadores se dividiu para a aplicação do instrumento, permitindo, por um lado, diminuir a sensação de "invasão" do espaço doméstico e, por outro, estabelecer uma relação mais intensa entre pesquisador e pesquisado. A escolha de qual pesquisador entrevistaria cada membro da família ocorreu previamente, tendo em vista as experiências anteriores e as habilidades dos entrevistadores.

\subsection{Observação e registro fotográfico}

Como instrumento complementar, a fotografia foi utilizada para registrar as propriedades, as casas, os ambientes de uso das TICs, bem como as próprias tecnologias estudadas. Admitimos que, neste primeiro momento, a imagem fotográfica foi apenas um recurso adicional de registro de informações sobre a realidade a ser investigada que não mereceu uma discussão mais aprofundada. O entendimento tácito entre os membros da equipe era de que a imagem funcionaria como uma ilustração do que estava sendo investigado.

Ao pedir permissão para fotografar o ambiente doméstico, a equipe encontrou resistência para registrar os cômodos mais íntimos, como quartos e banheiros. Porém, as famílias aceitaram que fossem fotografadas as salas de estar, cozinhas, ambientes externos da propriedade e a fachada da casa. Embora a equipe tenha acatado com naturalidade a situação, na verdade deveríamos ter prestado mais atenção à cultura das famílias no que diz respeito ao que se considera lícito mostrar - e, portanto, fotografar - e o que fica interditado à visão do fotógrafo ou até mesmo à sua invasão.

Durante o período de análise dos dados, os pesquisadores perceberam a importância de fotografar mais especificamente os aparelhos/artefatos - e não somente o local onde estavam posicionados ou sendo consumidos -, já que, ao manusear os dados coletados, algumas dúvidas sobre 
especificações técnicas surgiram e poderiam ter sido facilmente sanadas através das imagens. Se a imagem existisse, neste caso, ela funcionaria como um recurso metodológico que ativaria a memória do pesquisador e enriqueceria seus meios de observação.

Ainda a respeito dos registros fotográficos, também foi discutida e ressaltada a importância de não se levar equipamentos fotográficos muito grandes, bem como não utilizar o flash, diminuindo o risco de inibição e constrangimento dos entrevistados. A presença do mediador - que proporcionou o primeiro contato com as famílias - durante a primeira incursão a campo não permitiu que observássemos essa regra criada pelo grupo, já que ele, com sua câmera própria, fotografou os entrevistados durante a aplicação dos questionários sem pedir autorização dos mesmos e com uso do flash.

Reconhecemos, contudo, que tomar a fotografia como documento numa pesquisa social implicaria adentrar no debate polarizado entre aqueles que consideram a fotografia como evidência e os que a consideram construção. Nos termos de Martins (2008, p. 15), "de considerar a fotografia ou como objeto de conhecimento sociológico ou como seu instrumento".

É importante ressaltar, também, que os próprios pesquisadores se colocaram em atitude de "registro", ou seja, do início ao fim os investigadores tiveram o cuidado de observar em detalhes o contexto da pesquisa empírica, em especial o contexto doméstico, em que se dão os usos das TICs. Valladares (2007), a partir de Sociedade de esquina: a estrutura social de uma área urbana pobre e degradada (WHYTE, 2005), extrai o que chama de "dez mandamentos da observação participante". No sétimo mandamento, a autora fala que a observação implica "saber ouvir, escutar, ver, fazer uso de todos os sentidos" e que a coleta de informações não se restringe apenas a entrevistas. Desse modo, também esta incursão a campo buscou utilizar-se de impressões captadas pelos pesquisadores através da observação - que, posteriormente, compuseram o relato de campo. 
A seguir, refletimos sobre o "Relato de campo" e os "Perfis individual e familiar", que, diferentemente das técnicas recém-apresentadas, não são instrumentos de coleta de dados e sim procedimentos iniciais de análise de dados. Aqui fazemos uma exploração metodológica deles, discutindo seus usos para a pesquisa, descartando, neste momento, a preocupação com os dados empíricos que geram e que permitem as primeiras interpretações sobre a relação das famílias estudadas com os aparatos tecnológicos.

\subsection{Relato de campo}

Após a primeira viagem ao Vale do Sol, cada pesquisador foi instruído a escrever um relato de campo, que consiste na descrição de suas observações e percepções da conversa coletiva realizada com cada família e da aplicação dos formulários. Por ser uma pesquisa em equipe, o registro das impressões de cada membro é essencial para que essas informações não se percam e sejam sistematizadas e armazenadas para compartilhamento.

Observações acerca do ambiente e dos sujeitos pesquisados encontram espaço no relato de campo para serem descritas conforme o pesquisador bem entender. Travancas (2011, p. 103-104), ao falar sobre questões etnográficas práticas e teóricas, explica que o pesquisador "não é apenas um transmissor de falas ouvidas. [...] Seu papel fundamental é interpretar". Sob essa ótica, o relato de campo vem dar espaço à subjetividade do pesquisador, que é capaz de captar impressões e levantar questionamentos com base nos fatos, contextos e ambientes observados. Além disso, o relato de campo é o espaço reservado para as críticas e autocríticas em relação à aplicação dos instrumentos de pesquisa em campo, proporcionando um espaço de expressão e posicionamento. Além disso, esse exercício vai posteriormente constituir o que Brandão (2007, p.16) sugere como o primeiro passo em que se tenta articular explicações. Na nossa experiência, esse procedimento se concretizou nos perfis individual e familiar, apresentados a seguir. 


\subsection{Perfis individual e familiar}

Dentre os instrumentos de coleta de dados e de análise aqui explorados, os perfis individuais e familiares são os que mais se aproximam de um procedimento inicial de manuseio, organização e sistematização de dados sobre os usos das TICs pelas famílias relacionadas à cadeia agroindustrial do tabaco. Eles foram pensados como uma primeira etapa para análise dos formulários individuais e de família, servindo como uma articulação preliminar das informações obtidas por meio desses instrumentos. É, desse modo, um procedimento que já permite uma produção textual levando em conta os dados coletados ou o que Brandão (2007) considera como a primeira organização mais compreensiva dos dados. Mais uma vez, impõe-se o desafio da padronização de condut'las dentro do grande grupo.

A seguir, reproduzimos trecho de um dos perfis.

Perfil: Carmem ${ }^{11}$ V.

Filha de agricultores, Carmem, 30 anos, está casada com Demétrio há oito. Tem um filho, Pedro, também de oito anos. Convicta, apresentou-se como "agricultora, dona de casa, monitora escolar, mãe e esposa" [...].

Dos cinco irmãos, Carmem é a única que tem ensino médio incompleto, embora pretenda terminar. Seus pais concluíram apenas o quinto ano do ensino fundamental, mas suas duas irmãs terminaram o ensino médio $[\ldots]$.

Sobre as distintas tarefas que desempenha em sua rotina, ela conta que "abre os canteiros" para as mudas pegarem sol, dá comida para os porcos e cuida de todo o trabalho doméstico, como lavar roupa, arrumar a casa, cozinhar, entre outras. Além, é "claro", de "curtir o fumo", trabalho realizado no galpão. Comparando com as atividades de Demétrio, conclui, com certa naturalidade, que ele "fica mais na questão da lavoura, né"?

Em relação aos meios de comunicação que utiliza, destaca a TV e, especialmente, os telejornais da Globo, que "não pode perder". Ouve rádio sempre que está no galpão, durante o trabalho junto ao fumo [...].

${ }^{11}$ Pelos mesmos motivos explicitados na nota de rodapé $n^{\circ} 2$, os nomes dos integrantes das famílias foram alterados, sendo mantida apenas a primeira letra de cada um. 
O exemplo serve para mostrar como questões objetivas relativas a trabalho, nível de escolaridade e uso dos meios de comunicação, presentes no formulário individual, são utilizadas posteriormente na etapa de descrição e análise dos dados. Embora o objetivo não seja possuirmos um modelo único de perfil, excluindo características pessoais de escrita e aspectos específicos que se destacam para cada pesquisador, mantém-se uma base daquilo que se considera como essencial no procedimento. Por fim, entendemos que a produção de um perfil permite que todos os pesquisadores conheçam um pouco melhor todos os pesquisados, visto ser esse conhecimento estendido essencial para a análise dos dados.

\section{Considerações finais}

Para além da exploração empírica propriamente dita, ou seja, dos dados coletados nas visitas às famílias, as idas a campo nessa primeira fase da pesquisa tiveram como objetivo, por um lado, introduzir a equipe de pesquisadores à região da pesquisa, ou seja, tomar contato e conhecer a realidade a ser investigada para além da documentação bibliográfica já percorrida; e, por outro, refinar os instrumentos e estratégias metodológicas.

Sobre a vivência da pesquisa, a primeira experiência em campo serviu também para que os membros da equipe de pesquisadores se conhecessem melhor e pudessem perceber tanto as próprias atuações como entrevistadores(as) quanto as dos outros. Já a segunda incursão a campo proporcionou uma interação ainda maior com as famílias, aprofundando a questão dos usos dos meios de comunicação propriamente ditos. Em quaisquer das situações, entende-se que o trabalho de campo é uma vivência, com uma intensa dimensão de subjetividade (BRANDÃO, 2007), seja de relações interpessoais entre pesquisadores e pesquisados, seja entre os próprios pesquisadores e seus ambientes. Daí a importância de adotar o valor da reflexividade, que "deve fazer-se sobre as implicações desse cruzamento de referências sociais, de maneira a favorecer um melhor entendimento das dinâmicas que se desenvolvem nos espaços de interação" (NEVES e NOGUEIRA, 2005, p. 410). 
Decorre dessas experiências a necessidade de reiterar que a equipe precisa assumir os mesmos procedimentos de atuação, preservando as individualidades. Precisamos ter em vista que o grupo, em nosso caso, tem característica interdisciplinar, abrangendo membros com formações de diferentes áreas de conhecimento. Assim, o desafio da unidade de procedimentos torna-se ainda maior e não se pode perder esse objetivo de vista. Para isso, a equipe precisa intensificar as reuniões presenciais focadas nas técnicas de pesquisa, permitindo que se aprofunde o conhecimento sobre os instrumentos utilizados e se estabeleça um pacto de atuação. Desse modo, a condução do estudo pelos pesquisadores, pensamos, será a mais natural e segura possível.

Por fim, acerca dos dados coletadas sobre cada família, embora em um planejamento inicial entendêssemos que as duas visitas e as técnicas empregadas até aqui bastassem para acumularmos as informações necessárias sobre as duas famílias estudadas, pensamos ser necessário aprofundar ainda mais a exploração com esses pesquisados numa perspectiva histórica. Nessa direção, entendemos que seria muito rico tomar este primeiro momento como aquele de entrada de novos meios (telefone celular e computador, com ou sem acesso à internet) que se articulam a práticas já consolidadas (sobretudo relacionadas ao rádio e à televisão), ocasionando uma reacomodação das existentes, podendo ocorrer continuidades e rupturas.

De outro lado, entendemos que determinadas conclusões sobre o uso das tecnologias de comunicação por famílias agricultoras, no sentido de compreendermos certas apropriações como próprias desse universo, seriam mais legítimas por meio de um cruzamento deste estudo com outro, de mesmo caráter, a ser desenvolvido no meio urbano. Tal comparação pode oferecer importantes pistas sobre as especificidades de cada realidade, apontando distanciamentos e aproximações entre famílias rurais e urbanas. Esses são os novos desafios metodológicos que a pesquisa nos lança. 


\section{Referências}

BEAUD, S.; WEBER, F. Guia para a pesquisa de campo - Produzir e analisar dados etnográficos. Petrópolis: Vozes, 2007.

BRANDÃO, C. R. Reflexões sobre como fazer trabalho de campo. Sociedade e cultura, 10(1), p. 11-27, jan.-jun. 2007.

COULDRY, N. Media, society, world. Social theory and digital media practice. Cambridge: Polity Press, 2013.

My media studies: thoughts from Nick Couldry. Television \& New Media, v. 10, n. 1, p. 40-42, 2009.

. Why voice matters. Culture and politics after neoliberalism. Londres: Sage, 2010.

MARTÍN-BARBERO, J. Uma aventura epistemológica - Entrevista. Matrizes, v. 2, n. 2, p. 143-162, 2009.

MARTINS, J. S. Sociologia da fotografia e da imagem. São Paulo: Contexto, 2008.

MORLEY, D. Medios, modernidad y tecnología. Hacia una teoría interdisciplinaria de la cultura. Barcelona: Gedisa Editorial, 2008.

Televisión, audiencias y estudios culturales. Buenos Aires: Amorrortu, 1996.

NEVES, S.; NOGUEIRA, C. Metodologias feministas: a reflexividade ao serviço da investigação em ciências sociais. Psicologia: Reflexão e Crítica, 18(3), p. 408-412, 2005. SILVERSTONE, R. The sociology of mediation and communication. In: CALHOUN, C.; ROJEK, C.; TURNER, B. (Orgs.). The Sage Handbook of Sociology. Londres: Sage, 2005.

SILVERSTONE, R.; HIRSCH, E. (Eds.). Los efectos de la nueva comunicación. El consumo de la moderna tecnología em El hogar y em La família. Barcelona: Bosch, 1996.

TRAVANCAS, I. Fazendo etnografia no mundo da comunicação. In: DUARTE, J.; BARROS, A. (Orgs.). Métodos e técnicas de pesquisa em comunicação. São Paulo: Atlas, 2011.

VALLADARES, L. Os dez mandamentos da observação participante. Revista Brasileira de Ciências Sociais, São Paulo, v. 22, n. 63, p. 153-155, fev. 2007. Disponível em: http:// www.scielo.br/scielo.php?script=sci_arttext\&pid=S0102-69092007000100012\&lng=pt $\& n r m=i s o$. Acesso em: 20 abr. 2015.

VARELA, M. La dinámica del cambio en los médios. El miraba televisión, you tube. FLACSO, 2010 - Pós-graduação em Educación, Imágenes y Medios, 2010.

WHYTE, William Foote. Sociedade de esquina: a estrutura social de uma área urbana pobre e degradada. Rio de Janeiro: Jorge Zahar, 2005. 


\section{Sobre as autoras}

Ana Carolina Damboriarena Escosteguy - Doutora em Ciências da Comunicação pela Universidade de São Paulo (2000). Pós-doutorado no CAMRI (Communication and Media Research Institute) da University of Westminster (Reino Unido). Bolsista CNPq. Atualmente, é professora titular da Pontifícia Universidade Católica do Rio Grande do Sul e professora visitante do Programa de Mestrado em Comunicação da Universidad Católica del Uruguay (UCU).

Lírian Sifuentes - Pesquisadora no Departamento de Comunicação da Pontifícia Universidade Católica do Rio Grande do Sul. Doutora em Comunicação (2014) pela PUCRS, tendo realizado doutorado sanduíche no Departamento de Comunicação da Texas A\&M University. Realizou pós-doutorado (2014-2016) no Programa de Pós-graduação em Comunicação da PUCRS, pesquisando Metodologias de Pesquisa em Estudos Culturais.

Aline Bianchini - Doutoranda em Comunicação Social pelo Programa de Pós-graduação em Comunicação Social (PPGCOM) da Faculdade de Comunicação Social (FAMECOS) da Universidade Católica do Rio Grande do Sul (PUCRS) - Bolsista CAPES. Mestre em Comunicação Social (2013) pela mesma universidade.

Data de submissão: 15/05/2016

Data de aceite: 28/11/2016 